\title{
The Verbal Inventory
}

\subsection{Inventory of Forms}

The verbal system of Classical Arabic comprises a small number of simple verbal forms. The simple forms can be further augmented by modifiers or expanded by the auxiliary verb kāna. The morphological classification to simple, modified, and compound verbs does not reflect a functional hierarchy of more fundamental and more marginal forms; in a given syntactic environment, a modified or a compound form may prevail.

The opposition between a simple form and a modified or compound form can be either (a) functional, so that a semantic distinction is expressed by the simple and the non-simple form or (b) structural, so that the simple form is unmarked or ambiguous vis-à-vis the modified or compound form. The interpretation of the verbal form is sometimes imposed by the syntactic construction in which it is realized. In such case, the contrast between the simple and the non-simple form has to do with a certain (c) accentuation: the non-simple form provides an explicit expression to the meaning implied by the syntactic construction. Comparing, for instance, the simple yaf'alu and the modified $s a$ yaf'alu, we encounter these three possibilities (see also below 5.2.2.3):

$\begin{array}{llll}\text { a. yasma'u } & \text { He hears } & \text { sa-yasmáu } & \text { He will hear } \\ \text { b. yaqūlu } & \text { He says/will say } & \text { sa-yaqūlu } & \text { He will say } \\ \text { c. 'in dahala fa-yarāā } & \text { If he goes in he will see } & \text { 'in dahalafa-sa-yarāa } & \text { If he goes in he will see }\end{array}$

The verbal system of Classical Arabic presents a distinction in the desinence of the prefixed forms which is often captured under the label of 'mood' (see below 5.2.1). The moods, however, do not signal the semantic contrast between realis and irrealis. ${ }^{1}$ Rather, the forms belonging to the indicative system are modally unmarked and can express a wide range of meanings including desire,

1 Palmer, Mood and Modality, 4, defines mood-systems as 'basically ("prototypically") binary', marking the distinction between 'realis' and 'irrealis'. In Classical Arabic, however, this semantic distinction does not correlate with two separate sets of grammatical forms.

(C) MICHAL MARMORSTEIN, 2016 | DOI: 10.1163/9789004310483_006

This is an open access chapter distributed under the terms of the Creative Commons

Attribution-Noncommercial-Non-Derivative 3.o Unported (CC-BY-NC-ND) License 
possibility, and non-factuality. The modal forms, on the other hand, are much more limited in their semantic scope, and are used to indicate meanings which relate to the notion of volition. Modality, in particular the deontic type, can thus be conveyed by a marked or explicit form, such as the imperative or the energetic, or by an unmarked or implicit form, such as yaf'alu (see also below $5 \cdot 3)$ :

\begin{tabular}{lllll}
\hline tadhulu & You will/shall go in & udhul & Go in & (directive) \\
'adhulu & I will/shall go in & la-'adhulanna & I shall go in & (commisive)
\end{tabular}

Verbal negation in Classical Arabic cannot be regarded as a form of modification of the simple forms. For one thing, negation particles have a different distribution than verbal modifiers, e.g., they are compatible with interrogatives. For another, negation particles may trigger the use of a verbal form otherwise not occurring as an affirmative form in the same circumstances. Negation particles may also call for a certain interpretation of the verbal form which is uncommon with the affirmative form (see also below 5.4).

In the subsequent sections a survey of the inventory of the verbal forms in Classical Arabic is presented. First, the affirmative indicative forms are surveyed, then the modal and the negated forms are presented.

\subsection{Indicative Verbal Forms}

The verbal forms presented in this section are modally unmarked. They may be simple, modified, or expanded by the auxiliary verb kāna. Syntactically, they have a wide distribution and may figure in both independent and dependent clauses.

\subsubsection{Simple Forms}

There are two simple finite verbal forms: fa'ala and yaf'alu. The formal distinction between them lies in the position of their pronominal theme: facala has a suffixed pronoun, hence it is labeled the suffix conjugation; yaf'alu has a prefixed pronominal index, hence it is labeled the prefix conjugation. ${ }^{2}$ In fact, in

2 The prefixed pronoun exhibits a greater morphological degradation than the suffixed pronoun. For its description as indexical by the Arab grammarians, see above 4.5. 
the second and third person, a morpheme distinguishing gender and number is suffixed to the form. For this reason, yaf'alu is also labeled the circumfix conjugation:

TABLE 5.1 Suffix and prefix conjugations

\begin{tabular}{|c|c|c|c|c|c|c|c|}
\hline \multicolumn{4}{|c|}{ Suffix conjugation } & \multicolumn{4}{|c|}{ Prefix (circumfix) conjugation } \\
\hline \multicolumn{2}{|c|}{ sg. } & \multicolumn{2}{|c|}{ pl. } & \multicolumn{2}{|c|}{ sg. } & \multicolumn{2}{|c|}{ pl. } \\
\hline masc. & fem. & masc. & fem. & masc. & fem. & masc. & fem. \\
\hline \multicolumn{2}{|c|}{ fa'al-tu } & \multicolumn{2}{|c|}{ fáal-nā } & \multicolumn{2}{|c|}{ '-af'al-u } & \multicolumn{2}{|c|}{$n-a f^{\prime} a l-u$} \\
\hline fa'al-ta & fáal-ti & facal-tum & fa'al-tunna & $t-a f^{\prime} a l-u$ & $t-a f^{\prime} a l-\bar{\imath}-n a$ & $t-a f^{\prime} a l-\bar{u}-n a$ & $t-a f^{\prime} a l-n a$ \\
\hline fa'al-a & fa'al-at & fáal- $\bar{u}$ & fa'al-na & $y-a f^{\prime} a l-u$ & $t-a f^{\prime} a l-u$ & $y-a f^{\prime} a l-\bar{u}-n a$ & $y-a f^{\prime} a l-n a$ \\
\hline \multicolumn{4}{|c|}{ du. } & \multicolumn{4}{|c|}{ du. } \\
\hline \multicolumn{2}{|c|}{ masc. } & \multicolumn{2}{|c|}{ fem. } & \multicolumn{2}{|c|}{ masc. } & \multicolumn{2}{|c|}{ fem. } \\
\hline \multicolumn{4}{|c|}{ fáal-tumā } & \multicolumn{4}{|c|}{$t-a f^{\prime} a l-\bar{a}-n i$} \\
\hline \multicolumn{2}{|c|}{ fáal-ā } & \multicolumn{2}{|c|}{ fáal-atā } & \multicolumn{2}{|c|}{$y-a f^{\prime} a l-\bar{a}-n i$} & \multicolumn{2}{|c|}{$t-a f^{\prime} a l-\bar{a}-n i$} \\
\hline
\end{tabular}

The prefix conjugation consists of a set of forms, distinguished from each other in the quality of their final short vowel and in the presence of a final morpheme $-n$ or $-n n$ (with several allomorphs). These endings signal the moods of the verb. The indicative forms whose base ends with a consonant are signaled by the vowel $-u$; forms ending with a long vowel (the gender/number morpheme) are signaled by the -na/-ni ending. The feminine plural shows a different pattern, as it does not have a distinctive mood morpheme: 
TABLE 5.2 The moods

\begin{tabular}{|c|c|c|c|}
\hline Moods & sg. & pl. & du. \\
\hline$u$-form (indicative) & $y a f^{\prime} a l-u$ & $y a f^{\prime} a l-\bar{u}-n a$ & $y a f^{\prime} a l-\bar{a}-n i$ \\
\hline$a$-form (subjunctive) & $y a f^{\prime} a l-a$ & $y a f^{\prime} a l-\bar{u}$ & yaf'al- $\bar{a}$ \\
\hline$\varnothing$-form (jussive) & yaf'al & $y a f^{\prime} a l-\bar{u}$ & $y a f^{\prime} a l-\bar{a}$ \\
\hline$n$-form (energetic) & $y a f^{\prime} a l-a-n(n a)$ & $y a f^{\prime} a l-\bar{u}-n(n a)$ & $y a f^{\prime} a l-\bar{a}-n(n i)$ \\
\hline
\end{tabular}

Besides the two finite forms fa'ala and yaf'alu, the participle is another simple form pertaining to the verbal system. The participle is an adjectival pattern of the verb. It is non-finite in the sense that it does not embody a pronominal theme, but only gender and number markers. Syntactically, it behaves in principle like a nominal: (a) it takes case endings, (b) it is determined by the article or the tanwin, or (c) is bounded by a genitive complement. On the other hand, the participle, like finite verbs, may take an accusative complement.

As a predicative form with a verbal lexeme, the participle may enter the system of oppositions with the finite verbal forms. In such case, the participle does not serve a classificatory function: it does not assign a certain property to the theme, but it expresses its incidental state or disposition. ${ }^{3}$ Formally, the two functions are not always easy to distinguish unless the participle is determined by the article, a fact which precludes its verbal reading. ${ }^{4}$ Other adjectival patterns, such as facil and facil, derived mostly from stative verbs, can also enter the system of oppositions with the finite verbal forms (see below [8.14]). The participle and the 'participle-like' adjectives may be assigned either the nominative or the accusative case. As primary predicates, they take the nominative; as secondary predicates, they take the accusative.

\subsubsection{Modified Forms}

The modifiers are elements (perhaps of verbal origin) which co-occur with the simple verbal forms. The modifiers are: $q a d$, la-, and sawfa/sa-. They are

3 Beeston, Arabic Language, 66, defines 'classificatory predicates' as those 'assigning the theme to membership of a category'. Reckendorf, Zum Gebrauch des Partizips, 256-258, correctly observes that the participle is not inherently stative, but it indicates a state or disposition with respect to the theme.

4 A definite predicative participle has, according to Beeston's classification, an 'identificatory function', cf. Arabic Language, $66 \mathrm{ff}$. The participle assumes a verbal reading when it has deictic anchoring, i.e., when it is personally (hence spatiotemporally) bounded. 
distinct from clausal operators such as 'inna or 'anna (see below 6.2.2) in that they have only the verbal form, rather than the entire clause, in their scope. Verbal modifiers are generally incompatible with either negation or interrogation particles and pronouns. They have an affirmative function, yet it is hard to define their precise semantic meaning. $q a d$, la-, and sawfa/sa-operate in the domain of propositional modality: they express a degree of certainty or commitment with regard to the validity of the contents expressed by the verb. ${ }^{5}$ The interaction of $q a d$, la-, and sawfa/sa- with the simple verbal forms may result in the expression of certain temporal or aspectual meanings, although in most cases, these meanings are yet fraught with modal nuances. ${ }^{6}$ The use of some modified forms is restricted to specific syntactic structures, while the use of others is highly subjective and opened to a variety of syntactic environments.

The modifiers $q a d$, la-, and sawfa/sa- do not combine freely with all the verbal forms: the form yaf'alu is the only one compatible with all three modifiers. However, the co-occurrence of $q a d$ with facala is far more frequent (or far less constrained) than its co-occurrence with yaf'alu, as summarized in table 5.3:

TABLE 5.3 The verbal modifiers

\section{Modifiers fáala yaf'alu fä́ilun}

\begin{tabular}{llll}
\hline qad & + & + & - \\
la- & - & + & + \\
sawfa/sa- & - & + & - \\
\hline
\end{tabular}

\subsubsection{The Modifier qad}

The use of qad fa'ala is far more extensive than that of qad yaf'alu. In fact, rather than being a sheer modification of the simple fáala, qad fa'ala has acquired

5 Palmer, Mood and Modality, 68-69, discusses cases in which markers of modality combine with declaratives so as to indicate strong assertion or various degrees thereof. Lyons, Deixis and Subjectivity, 110, mentions the modal particles of German as an example for a nonobligatory albeit very common device to express 'the speaker's attitude or degree of commitment', in clauses that are unmodalized or declarative.

6 The assumption that the modifiers had originally a modal (assertive) function is corroborated by the fact that some modified forms, e.g., la-yaf'alu and qad yaf'alu, are not found in dependent clauses. The opposite also holds true: when a modified form occurs in a dependent clause, it loses much of its modal force in favor of the expression of temporal and aspectual nuances. 
the status of a verbal form in its own right. This can be established in view of its relationship with the simple fa'ala and by comparison to the modified qad yaf'alu.

The syntactic distribution of fa'ala is distinct from that of qad fa'ala. Both forms belong to the same substitution class in affirmative independent clauses and in substantival and adjectival clauses. However, adverbial and predicative clauses (see below chapter 8), show a strong tendency to favor either facala or qad fa'ala, or feature only one of them (we recall that qad fa'ala almost never occurs in interrogative and negative clauses, for exceptions see [9.76], [9.83]). In these clauses, facala and qad facala partake in different systems of oppositions, so that (synchronically speaking) the second cannot be regarded as a further extension or specification of the first.

Not only in terms of frequency, but also as far as syntactic and lexical features are concerned, qad fa'ala has a far larger scope of application than qad yaf'alu. The modified form qadyaf'alu, as opposed to qadfa'ala, does not occur, in principle, in dependent clauses. It is not used with every lexeme. In dialogues, qad $y$ af'alu is occasionally found with the verbs ra'ä 'to see/comprehend', 'alima and 'arafa 'to know' (see below [9.16]); otherwise, it is mostly used in generic utterances (see below [11.5]). Furthermore, the syntactic juncture of qad and yaf'alu is less tight than that of qad and fa'ala: in kāna-compounds, qad precedes as a rule the auxiliary with $y a f^{\prime} a l u$ (the same as it precedes the auxiliary with the participle), whereas it is often interposed between the auxiliary and fa'ala (see below 8.2.1):

TABLE 5.4 qad fa'ala $v$ s. qad yaf'alu

\begin{tabular}{lll}
\hline & qadfáala & qadyaf'alu \\
\hline Frequency & high & low \\
Dependency & independent/dependent cl. & independent cl. \\
Lexical class & not limited & limited \\
Juncture in compounds & $\begin{array}{l}\text { kāna qadfáala } \\
\text { qad kānafáala }\end{array}$ & qad kāna yaf'alu \\
\hline
\end{tabular}




\subsubsection{The Modifier la-}

The modifier la-co-occurs with either yaf'alu or the participle in clauses introduced by the operator 'inna (see below 6.2.2.2). Clauses introduced by inna are either independent or enclosed in larger syntactic frames, following the conjunction hattā or the circumstantial $w a$-. The operator 'inna may also head a mutually dependent construction (see below 8.4). Only in very rare cases, yaf'alu preceded by la- occurs outside the frame of an 'inna-clause.

The verbal form fa'ala may also be preceded by an element la-in the apodosis of a conditional construction or in the content clause of an oath. Although formally identical, this $l a$ - has a different distribution than the verbal modifier $l a$-. The $l a$ - of ğawāb 'apodosis' introduces the second part of a conditional construction initiated by the particle law (or lawlā), or it may precede a protasis introduced by 'in. The apodotic la- may also introduce the content of an oath. This is explained by the fact that the oath and its content are structurally similar to a condition, having two interconnected parts. ${ }^{7}$ The apodotic $l a$ - is prefixed to facala or to the energetic. It has in its scope the second clause of a bipartite construction. In contrast, the verbal modifier la-, known as the la- of tawkid 'emphasis', is prefixed either to yaf'alu or to the participle (see below 9.2.3), ${ }^{8}$ and has in its scope the predicate of a single clause. That the apodotic $l a$ - and the emphasizing $l a$ - are functionally distinct is corroborated by the fact that the first can precede the negated form $m \bar{a}$ fa'ala (law fa'ala ... lā-mā fa'ala ...), while the latter is incompatible with negation. ${ }^{9}$

Modifiers can be accumulated: $l a$ - may be preposed to the modified form qad fa'ala or to the modified compound form qad kāna+V. The fact that la-may be preposed to qad fa'ala evidences the tight juncture of qad and fa'ala that allows the construction to be put as a single unit in the scope of another verbal modifier..$^{10}$ la-qad fáala occurs in various syntactic structures, among which

Sadan, $\breve{G} a w \bar{a} b$, reviewing the use of the technical term $\check{g} a w a \bar{a} b$ in the Arabic lexicographical and grammatical tradition, renders it as 'an utterance following another utterance'. The adduced examples show, however, that a ğawāb is not just a consecutive clause, but has an intrinsic semantic relation to the preceding clause (or part of clause). The meaning of ğawāb should be therefore understood in a stricter sense, as a consecutive clause in a bipartite construction.

$8 \quad l a$-is not limited to verbal or adjectival forms only. It can also precede prepositions.

9 For a detailed survey of the various taxonomies of the occurrences of $l a$ - proposed by the Arab grammarians, see Testen, Asseverative la-, $1-56$.

10 Wright, Grammar, 2, 19, quotes one example of the modifier la-preposed to sawfa. Such cases were not found in my corpus. 
are the apodosis of $l a w$-conditionals and oath expressions. In the latter case, la-qad fa'ala is far more common than la-fa'ala. ${ }^{11}$

\subsubsection{The Modifier sawfa/sa-}

The modifier sawfa, or its shorter and more common form sa-, is only compatible with yaf'alu. The modified form sawfa/sa-yaf'alu can occur in independent clauses (see below [9.17]), in substantival clauses linked by 'anna (see below [7.5]), and in raising constructions (see below [8.73]). It is also quite common in apodotic or comment clauses introduced by $f a$ - The modified form sawfa/sayaf'alu refers to a posterior event. The posterior meaning of sawfa/sa-yaf'alu arises most clearly with stative verbs, which would otherwise have a concurrent reading with the simple $y a f^{\prime} a l u .{ }^{12}$ In other cases, e.g., in the apodosis of a conditional construction or in a comment clause, the modifier sawfa/sa-does not contribute to a temporal disambiguation or specification of $y a f^{\prime} a l u$, since the meaning of posteriority is already imposed by the syntactic structure. In such cases, the modifier sawfa/sa- may be said to serve as a heavier means by which the meaning of posteriority is expressed.

\subsubsection{Compound Forms}

A compound verbal form consists of the auxiliary verb kāna and the simple verbal forms fa'ala, yaf'alu, the participle (assigned the accusative), or the modified form qad fáala. ${ }^{13}$ The auxiliary kāna, as opposed to the verbal modifiers, has in its scope a full clause, either nominal or verbal, and even an entire paragraph. It may immediately precede its predicate or it may initiate a long chain of predications, without being repeated. Thus, the realization of kāna-clauses, or more specifically of kāna-compounds, often takes place at the text level, as the 'minimal' clausal structure is extended to a multi-clausal stretch.

The auxiliary verb kāna operates as a temporal or a modal adapter: it adjusts the predicate to the deictic point of reference (see above 4.2), so that the predicate is left to indicate aspectual distinctions. One can distinguish between four

11 It appears that the preference of either la-fa'ala or la-qadfa'ala is in part lexeme-sensitive, cf. Kinberg, Qad.

12 The technical use of the term 'concurrent' in this work is explained below, see 7.2.

13 Modifying verbs other than kāna combine with simple verbs and form verbal complexes. However, these verbs are distinguished from kāna in that: (a) they impart an additional overlay of meaning to the temporal or modal meaning conveyed by kāna; (b) they are rather constrained in their possible combinations with a content verb, often combined only with yaf'alu. 
manifestations of the auxiliary: the 'anterior' kāna, the 'posterior' yakūnu, the 'subjunctive' 'an yakūna and the 'conditional' 'in yakun/käna. As far as their function is concerned, the latter two manifestations should have been presented together with the other modal forms. However, as the current discussion focuses on formal aspects of the verbal inventory, they will be subsumed under this section as well.14

The anterior kāna locates its predicate in a point previous to some other reference point. It can precede all the simple forms and the modified qad fa'ala (see below 8.2.1). Anteriority can also be syntactically marked, by the asymmetrical juxtaposition of a matrix clause and a dependent clause (see below 6.1.2). Occasionally, the morphological and the syntactical markers converge, i.e., when a kāna-compound occurs in a dependent clause (see below [7.13], [7.14], [7.31], [7.33], [7.52]-[7.54], [7.77], [7.78], [7.80]).

The posterior yakūnu is far less common than the anterior kāna. Interestingly, it is not attested with the simple forms fa'ala and yaf'alu. It does precede the participle and the modified form qad facala.

The subjunctive yakunna and the conditionals yakun/kāna accommodate the simple verbal forms into a fixed clausal pattern, triggered by operators such as 'an or 'in. The subjunctive 'anyaküna is constructed with fa'ala, the participle, and qad fa'ala. Interestingly, in my corpus, 'an yakūna fa'ala stems from the Ta'rīh and Majāazi texts, while 'an yakūna qad fa'ala is mostly found in the Buhalä text.

The conditional yakun/käna form compounds with all the simple forms and the modified form qad fa'ala. ${ }^{15}$ The verb kanna can also precede the conditional particle. In such cases, its scope is extended to the entire conditional construction. Like the subjunctive, yakun/kāna allow forms which otherwise do not follow directly the conditional particle, viz., yaf'alu, the participle, and qad fa'ala, to occur in the clause. ${ }^{16}$ The use of fáala after kāna brings about

14 The relatively uncommon mā kāna li-yaf'ala, involving the so-called lāmal-ğuhūd 'the lām of denial', will not be discussed in this section.

15 The term conditional does not refer here to the semantological notion of conditionality ('possible and non-necessary') but to a formal structure which is common to both hypothetical conditional constructions and non-hypothetical or temporal constructions. All these constructions exhibit the bipartite pattern fa'ala fa'ala, which is introduced by particles such as 'in, law, 'i $\underline{d} \bar{a}$, and lammāa, and such pronouns as man, $m \bar{a}$, kullamā, etc. Proper conditional constructions introduced by 'in, or one of the pronouns embodying 'the meaning of 'in', exhibit also yaf'al forms.

16 The conditional particle law appears to be less restrictive than 'in, allowing qad fa'ala and yaf'alu (with certain lexemes) to follow it directly. 
the opposition between the simple fa'ala and its compound counterpart kāna fa'ala. Within a conditional clause, this pair of forms does not mark the temporal opposition 'past': 'anterior past', but serves to indicate other oppositions. For instance, in 'id $\underline{a}$-constructions, fa'ala may depict an habitual occurrence which is temporally unbounded, while kāna fáala depicts a past habitual occurrence. In conditionals introduced by 'in, the same pair indicates the modal distinction between hypothetic-yet-realizable events (with an implied future time reference) and impossible or unrealizable events (with an implied past time reference). In conditionals introduced by law, the simple fa'ala and the compound kāna fa'ala can be said to be distinct only in terms of markedness, since law dictates as a rule the impossible or unrealizable reading of the clause.

The anterior kāna and the conditional kāna may appear in a reductive analysis as one and the same thing: in both cases, kanna locates the verbal situation in a previous, actual or hypothetical, point in time. However, one can adduce a number of arguments against this analysis: (a) the conditional kāna forms a substitution class with the apocopate yakun and not with yakūnu, as elsewhere in the system; (b) the hypothetical sense of kāna arises not only in conditional clauses, but also in other types of clauses, where it forms compounds with yaf'alu and the participle (see below [7.76], [7.81]); and (c) the conditional kāna does not indicate a step back in time, neither in 'in nor in law-conditionals: 'in kāna yaf'alu/ fãían has an implied non-past reference while law kāna fáala has the same past time reference as law fáala. Table 5.5 below summarizes the above discussion on compound kāna forms:

TABLE 5.5 Compound kāna forms

\begin{tabular}{lcccc}
\hline Auxiliary & fáala & yaf'alu & fä́ilan & qadfáala \\
\hline 'anterior' kāna & + & + & + & + \\
'posterior' yakūnu & - & - & + & + \\
'subjunctive' 'an yakūna & + & - & + & + \\
'conditional' 'in/'í⿴囗十a/law yakun/kāna & + & + & + & + \\
\hline
\end{tabular}




\subsection{Modal Verbal Forms}

In a broad definition, the term modality refers to the expression of 'certain attitudes of the mind of the speaker towards the contents of the sentence.'. ${ }^{17}$ Modality, in this sense, converges to a large extent with the notion of subjectivity, and thus may be considered as omnipresent in language. ${ }^{18}$ In a more restrictive view, modality is regarded as the semantic domain corresponding to the grammatical category of mood (or some other formally defined category) ${ }^{19}$ The category of modality covers thus only a certain part in the realm of subjectivity; the other, more elusive (and far less studied) part, is occasionally referred to as expressivity. In the traditional view, modal forms are classified into two basic types: epistemic and deontic. ${ }^{20}$ According to more recent diachronic and typological studies of modality, four types of modality can be distinguished: agent-oriented, speaker-oriented, epistemic, and subordinating. ${ }^{21}$

In Classical Arabic, modality is often expressed through the verbal forms. ${ }^{22}$ The verbal system consists of indicative and non-indicative moods. The indicative forms have a broad grammatical and semantic scope of application: (a) they are realized in both independent and dependent clauses, and (b) they are modally unmarked, so that they may be used to express both assertive and non-assertive meanings. Deontic modal forms are found only in independent clauses. The subjunctive, on the other hand, is never found in independent

17 Jespersen, Philosophy, 313 .

18 Lyons, Deixis and Subjectivity, 102, defines subjectivity in a very similar way as 'the way in which natural languages, in their structure and their normal manner of operation, provide for the locutionary agent's expression of himself and of his attitudes and beliefs'.

19 Narrog, (Inter)subjectification, 392-393, argues against the definition of modality in terms of 'speakers' attitudes and subjectivity', since 'the means of expression of the speakers' attitudes are far too varied to be subsumed under one category label'.

Palmer, Mood and Modality, refines this classification by drawing a basic distinction between 'propositional' and 'event' modality, which in a modal system are further divided into 'epistemic' and 'evidential', 'deontic' and 'dynamic', respectively.

21 Bybee, Perkins, and Pagliuca, Evolution, $177 \mathrm{ff}$. The authors comment that agent-oriented modality, though part of the propositional content of the clause, is still included in their study, since 'these modal senses are the diachronic sources of most senses that Do qualify as modality in other studies'. Narrog, (Inter)subjectification, proposes yet another model of modality, consisting of two dimensions: a dimension of 'volitivity' and a dimension of 'speaker-orientation'.

22 Although modality is often expressed by verbs, it can also be indicated by other grammatical means such as the modal particles layta and lacalla, which are used to express wish and possibility, respectively. 
clauses. Its use is not determined by semantic or pragmatic considerations, but by the syntactic structure of the clause.

The modal forms indicating deontic modality are the imperative if $a l$, the jussive li-yaf'al, and the energetic la-yaf'alanna. The imperative has the same base form as the apocopate form $y a f^{\prime} a l$, without the prefixes. It is inflected for the second person only. The jussive is one manifestation of the apocopate form $y a f^{\prime} a l$, preceded by the conjunction $l i-.^{23}$ The apocopate $y a f^{\prime} a l$ has yet another modal use: it functions as a conditional form (see also below). ${ }^{24}$ In fact, yaf'al may be described as the non-assertive form par-excellence: it occurs only in the frame of 'mands' (command, request, etc.), conditions, or negations. ${ }^{25}$ The energetic has the same base form as the subjunctive yaf'ala, with the addition of the 'energic' suffix $-n(n a)$. The energetic, often following expressions of oath or serving as the apodosis of law and la-in conditionals, is preceded as a rule by the 'apodotic' la-.

The subjunctive yaf'ala occurs in dependent and embedded clauses. As such it differs to a great deal from the deontic forms, which occur as a rule in main clauses. As a dependent form, the subjunctive is merely propositional and therefore deprived of subjective illocutionary force. It is triggered by a set of operators and its use is determined by the overall syntactic structure of the clause. ${ }^{26}$ The subjunctive occurs in complement clauses of mental verbs or in consecutive and final clauses introduced by hattāa, 'anna, and li- (and complex forms thereof). However, the subjunctive may also occur in a clause conveying an entailed, sequential, or responsive meaning. In these cases the subjunctive follows particles such as the sababiyya 'causal' $f a$ - or 'idan and marks modal congruence with the first part of the construction, which indicates a non-assertive (imperative, hortative, negative, interrogative) meaning (see also below 10.2.3).

23 In accordance with the traditional view (cf. Wright, Grammar, 1, 291), li- preceding the mağzūm and the manșūb forms is viewed here as different from the preposition li- preceding nouns. One formal difference between the two is the elision of the vowel $i$ when $l i$-, prefixed to the mağzumm, is preceded by $f a$ - or $w a$ - (e.g.: $\left.f a-l-y a f^{\prime} a l\right)$. li-can be prefixed to the verbal form or it can be adapted to it by another conjunction, such as 'an and kay.

24 The conditional $y a f^{\prime} a l$ is distinct from the jussive $y a f^{\prime} a l$ both grammatically and semantically: (a) it is not conjoined with $l i-;$ (b) it participates in a mutually dependent construction (conditional construction); and (c) it does not indicate deontic modality.

25 Giolfo, Yaqum vs. Qāma, 156-158, proposes an overall analysis of the verbal system in Classical Arabic, based on the contrast between 'certainty' and 'uncertainty'. In this analysis, $y a f^{\prime} a l$ is the least 'certain' form, pertaining to the domain of 'virtual uncertainty'.

26 For a comprehensive discussion of the subjunctive in Classical Arabic, see Sadan, Subjunctive Mood. 
The indicative forms, though generally not marked for modality, may have in certain cases a specific modal function. This function is not viewed here as secondary to the main indicative or assertive function, but as yet another application of the same grammatical form. facala expressing optative meaning is a case in point. Optative clauses are characterized by a distinct syntactic pattern (see below 9.4). In these clauses, fáala expresses a kind of volition (a personal wish projected on God) that is never conveyed by the modal forms. Another case where facala has a modal function is in conditional constructions. ${ }^{27}$ The paradigm of facala and the apocopate $y a f^{\prime} a l$ is used in both the protasis and the apodosis of the basic 'modally interdependent' conditional structure: 'in yaf'al/fa'ala yaf'al/ fa'ala. ${ }^{28}$ Table 5.6 below summarizes the above discussion on the modal forms:

TABLE 5.6 The modal forms

\begin{tabular}{lll}
\hline Deontic & $\begin{array}{l}\text { imperative } \\
\text { jussive } \\
\text { energetic } \\
\text { optative }\end{array}$ & $\begin{array}{l}\text { if'al } \\
\text { li-yaf'al } \\
\text { li-yaf'alanna } \\
\text { fáala }\end{array}$ \\
Neutral & subjunctive & yaf'ala \\
Epistemic & conditional & yaf'al; fáala \\
\hline
\end{tabular}

\subsection{Negated Verbal Forms}

Negation in Classical Arabic cannot be simply regarded as a modification of the simple or compound verbal forms. Certain negation particles may trigger the use of a verbal form not having an affirmative counterpart used in the same circumstances. Or, they may impart to the verb a temporal or a modal sense that

27 For an analysis of the semantic opposition between facala and yafal in conditional constructions, see Giolfo, Yaqum vs. Qāma.

28 Peled, Conditional Structures, 9, describes the relationship between a fáala/yaf'al protasis and a fa'ala/yaf'al apodosis as 'modal interdependence': each part induces the conditional sense of the other. Modal interdependence is contrasted with 'modal split', where each part of the construction indicates different modality. 
is not indicated by the affirmative form. For these reasons, the negated forms are better viewed as a system of their own (see below 9.2.4).

The negation particles attested in the corpus are la , māa, laysa, lam, lan and $\dot{g}$ ayr. The most basic particle $l \bar{a}$ is detectable in other more complex negation particles (e.g.: * la-'aysa, *la-ma, * $\left.l a-{ }^{\prime} a n\right)$. Also in its distribution, la is the most common negation particle, in both main negations and secondary or double negations ('neither ... nor ...'), where it functions as the default negation particle, regardless of the form which the first negation assumes.

Some negation particles, such as $l \bar{a}, m \bar{a}$, and laysa, are compatible with more than one verbal form. $l \bar{a}$ can negate the indicative forms fa'ala, yaf'alu, and (rarely) the participle, as well as the modal forms yaf'al and yaf'alanna. mā negates all the indicative forms while laysa can only negate yaf'alu and the participle. Other negation particles are form-specific: lam is compatible only with yaf'al, lan with yaf'ala, and gayr with the participle (as with other nominal forms). The combination of a certain negation particle and a verbal form marks various kinds of negations. Thus, lam+yaf'al indicates past negation while $l \bar{a}+y a f^{\prime} a l$ functions as prohibitive. The particle lan negates yaf'ala in main clauses, whereas in dependent clauses yaf'ala is negated by $l \bar{a}$.

The negation of the participle is often doubly marked: besides the negation particle $m \bar{a}$ or laysa, the participle can be preceded by the preposition $b i$-, assigning it the genitive case. This structure is designed to express a strong negation of both the 'nominal' and the 'verbal' participle: in the first case, it indicates the dissociation of a certain property and the theme; in the latter, it emphasizes the negation of a certain state or disposition of the theme (both readings may conflate, see below [9.52]). Table 5.7 below summarizes the above discussion on verbal negation:

TABLE 5.7 Negated verbal forms

fáala yaf'alu fã́ilVn yaf'al yaf'ala yaf'alanna

\begin{tabular}{lllcccc}
\hline la & + & + & $(+)$ & + & {$[$ 'an cl. $]$} & + \\
ma & + & + & $+[b i-]$ & - & - & - \\
laysa & - & + & $+[b i-]$ & - & - & - \\
lam & - & - & - & + & - & - \\
lan & - & - & - & - & + & - \\
gayr & - & - & + & - & - & - \\
\hline
\end{tabular}


A compound form is negated once: either the auxiliary verb or the content verb is negated. The following negation patterns are attested in the corpus:

TABLE 5.8 Negated compound forms

\begin{tabular}{|c|c|c|}
\hline Negation & Auxiliary & Content \\
\hline lam & yakun & $\begin{array}{l}\text { fa'ala } \\
\text { yaf'alu } \\
\text { fácilan }\end{array}$ \\
\hline$m \bar{a}$ & kāna & $\begin{array}{l}\text { yaf'alu } \\
\text { fāiilan }\end{array}$ \\
\hline Auxiliary & Negation & Content \\
\hline kāna & $l \bar{a}$ & $\begin{array}{l}\text { yaf'alu } \\
\text { fāilan }\end{array}$ \\
\hline kāna & $\dot{g} a y r$ & fāiilin \\
\hline
\end{tabular}

\section{$5 \cdot 5 \quad$ Summary}

In this chapter, I have presented the inventory of the verbal forms in Classical Arabic. The classification of the forms was based mainly on their morphosyntactic properties, although some semantic features were also taken into consideration. The forms were accordingly characterized with respect to their being: (a) affirmative or negated, (b) indicative (modally unmarked) or modal, (c) simple, modified, or compound. In the subsequent chapters, the formal and the functional properties of the verbal forms, specifically those constituting the indicative paradigm, will be further discussed and illustrated. 